\title{
Spider monkey in Taricaya
}

\author{
Fan Xia ${ }^{1,}$, Shiyu $\mathrm{Fu}^{2}$, Ziyun $\mathrm{Qi}^{3}$ \\ ${ }^{1}$ International Department Senior 2 Class 1, Suzhou, China \\ ${ }^{2}$ Ulink-Beijing ASC, Beijing, China \\ ${ }^{3}$ The Education University of Hongkong, Hongkong, China \\ *Email: 1332812390@qq.com
}

Keywords: Spider Monkey, Taricaya, animal reserve

\begin{abstract}
This summer vacation, from August 4th to 18th, we had experienced being as a volunteer in an animal reserve which also works as a rescue center of wild animals in a part of the forest which called Taricaya (the Spanish name of a specific kind of turtle that the animal reserve in Taricaya mainly protects). Through the introduction of the staffs in Taricaya, we learned that there used to be a special kind of monkey called spider monkey in this area, which plays a very important role in the rain-forest. Since the monkey is locally extinct in Taricaya, the biologists which mainly come from Britain are trying to reintroduce the spider monkey into this area. For further information, we interviewed one of the experts who is in charge of the reintroduction program of spider monkey in this animal reserve, asking him about how this program operates and the behaviors of the monkeys during this period.
\end{abstract}

\section{Introduction}

The Amazon Rain Forest is located in the Amazon Plain of South America, covering an area of 7 million square kilometers. This rain forest strides over eight countries: Brazil (60\% of the forest area), Colombia, Peru, Venezuela, Ecuador, Bolivia, Guyana and Suriname, taking over half of the world's rainforest area and occupying $20 \%$ of the world's forest area. The Amazon rainforest is the world's largest tropical rainforest with a total area of 7 million square kilometers which contains substantial amount of the species. The Amazon rainforest is vital to the health of the world and all living creatures in the world. This rainforest is the home of $1 / 5$ of the world's species. The species of birds and plants account for half of the total amount of species in the world. Plus, the freshwater resources occupy $18 \%$ of the world's total freshwater resources. There are more than 2000 species of freshwater fish in the river, which are valuable resources for human beings. At the end of the 9th century, according to a British naturalist, there were 14,712 species of animals, more than 8,000 of which were unknown. There were more than 100,000 known species of animals and birds, and perhaps millions more are waiting for discovery. Therefore, the impact of the Amazon basin on global climate and ecological environment is significant.

\section{The introduction of spider monkey}

Spider monkey is a kind of New World monkeys (one of the families of primate) belonging to 
the genus Ateles, part of the subfamily of Atelinae. They are found in tropical forest, especially in the South America Central. The genus includes seven different species and all of them are threatened, especially when it comes to black-headed spider monkey (the one which experts in Taricaya are trying to re- introduce) and the brown spider monkey. They are social animals and live in group of up to 35 individuals. While they are foraging during the day, they will spilt up in order to get the maximum amount of food. The recent study of primate cognition shows that the spider monkeys are the most intelligent one among new world monkeys.

It is worth noting that the spider monkeys have four fingers, while the others have five. Plus, they have very long and strong tails which the last part of the tails is without fur, and the tails are strong enough to support the whole body. Therefore, we always see them hanging on the sticks of the trees just by their tails, and when we look at them form the ground, they just look like a spider. That's why we call them spider monkeys.

The hands without the thumb also make them more convenient to grab the branches and moving through the trees. So the four-fingered hands and the robust tails help them to live in the canopy (the highest part of the trees) of other higher part of the trees since the branches there are strong enough to support their weight, while the other animals use the other lower part of the forest. The another difference between the spider monkeys and the other monkeys is the size. The spider monkeys are the biggest primates in this area. Male spider monkeys can normally weight $10 \mathrm{~kg}$. Different kinds of spider monkeys usually have different fur color. The one in the animal reserve of Tariya has black fur, and for example, the white Belly spider monkeys is yellow. The species of spider monkey in different regions usually get different fur color.

\section{The unfavorable situation of spider monkey}

A large quantity of people in Peru live on logging and mining. They will take boats to the forest every day, and usually with a gun. When they meet the group of spider monkey in the forest, they will shot at them and eat the biggest one. The spider monkey is also a very major food source for the local people due to their large sizes. And if the biggest one carries a baby, the people will bring the baby home after eating the mother monkey and treat the baby like a pet. And also, the behavior of logging and mining by the local habitants threat spider monkey by losing their habitats. Spider monkeys are also be used in laboratory experiments. However, the reproductive cycle of spider monkey is long and the fertility rate is quiet low. The female monkeys need to spend time between 5 to 8 years to be fertilized, and get its first baby. Then they can get the second one in at least three years. That is the reason why they cannot recover this huge amount of loss of spider monkeys, which finally causes this locally extinction in Taricaya. The spider monkey is indispensable to the ecosystem but many species of them in different countries around America are now considered as endangered species or even critically endangered species. The IUCN Red List lists one species of the spider monkey as vulnerable, four species as endangered and two species, one in Columbia and one in Peru (the one that the experts in Taricaya are trying to re-introduce), are down for two of the 25th most endangered primate in the world. Because of their big size, people hunt them for several purposes.

\section{The important role of spider monkey in the tropical rain-forest}

The existence of spider monkeys is of great importance to the ecological environment of the rainforest. That is because they are the only species that can carry the big seeds (which has a diameter greater than 1 centimeter) of a particular species of trees. In details, they usually swallowed the whole seed and travel a long distance before they released the seed. The existence of spider monkey helps the trees propagate their seeds from one part to other parts of the forest, and 
the trees provide food that they need every day for energy. This kind of relationship which called mutualistic symbiosis is quiet a commonplace in such a kind of ecological environment. If spider monkey extinct, or at least disappear in this region, the trees with big seeds cannot spread their seeds, growing any burgeon. This will destroy the balance system of the forest. As time passes, old trees die but no new sprouts germinate, the quantity of the species will decrease drastically and leads to the final die out. The extinction of certain kind of trees will continue giving rise to a serious, unbelievable impact on biodiversity in tropical rain forest. Species and species in the forest have tight connection with each other. With the lack of this kind of trees, the species which relied on these trees will be endangered or even extinct because of lacking of food. The extinction of one species leads to the extinction of another species that depend on them, and repeat as a cycle. This will be a severe runaway chain reaction.

Finding out whether there has spider monkeys or not is a very important factor of determining whether the condition of this region of forest if good or not. If there are no more spider monkeys that mean the forest have experienced some artificial hunting or disasters. Therefore, these biologists come there and built a program called spider monkey reinstruction, in hopping the spider monkeys can come back and live in this place again.

\section{The detailed information of the reintroduction program}

Taricaya is an area which is known that there are spider monkeys before. And the rescue center is known and also supported by the local government, the staffs there train and give the monkeys the skills to return to the forest in the center. And they can't release the spider monkey if the individual one has some kinds of diseases that have been infected by contacting with human during the period of being a pet. Since these diseases might popularize by the single monkey to the whole group even the whole species. That will give rise to a severe consequence. All the animals arrived there must have a guarantee period (or called observation period, the animal has been put alone in one cage) since the staffs need to make sure that the animal is clean, healthy and in good condition. Then the animal can be put into cage with other animals. If the monkey they found has some diseases that infected by human, they normally take the way of euthanasia. There are too many risks of releasing animal with the diseases into the forest. And the risk of treading is also huge. Maybe the disease will not kill the spider monkey, but it may harm other species in the forest or may even lead to death. Thus they have to make sure that there are not any negative impacts to the other population in the forest if the animal contacts with other animals. It's the step of great importance.

After ensuring that the group is clean, they are preparing to release. The species like the monkey, staffs usually put a collar with transmit device that can send signal in order to get their location easily. But for the senior monkey, they are strong enough to break the collar so that it will be more difficult to locate them. The monitoring evaluation system will help them to find out their adaptation process, to collect data and see how they work when they arrive the unacquainted circumstance.

In 2011, the experts in Taricaya successfully released the first group of the selected spider monkeys. And then in 2014, they added some new individuals to that released group. This group are now living together and growing together. Since then, they reported 7 babies which are born in the wild from the group of monkeys that they introduced to the jungle. These spider monkeys were previously living the same as the spider monkeys in the cages in camp that we can see now. They spent the same period, and then the experts did many evaluation tests like behavior tests and veterinarian tests to check whether they are good to release. After they found out the spider monkeys were ready, they released them, monitoring them until they saw that all of them were in good condition. In 2018 November, the staffs in the animal reserve are going to release second 
group.

The expert who takes charge the part of releasing spider monkey told us that he has couldn't find the recently released group for nearly two weeks. It is weird since previously they can meet the monkeys almost every day so long as they tried to find them. The staff who collects the data of the forest was looking and walking everywhere but he still cannot find them. He told us there must be something happened to this group.

The whole process which reintroduces spider monkeys to the wild is called adaptation process. First, they need to select good individuals, and train them to work as a group, because wild monkeys always live in a group. Wild spider monkeys always have 24 to 25 members in a group. All the groups of the monkey have a leader, and it is worth to point out that the leader of spider monkeys can be both female or male, although usually the leader is a male. After releasing them, the experts will follow the monkeys and find out whether they are in good condition or not. To make sure of this, they will stay with monkeys in the deep part off the jungle. The experts will give a hand when the monkeys need help and collect the data about what the monkeys do; when they first go into the forest and how they adapt to the new life. After a period of time, some individuals will adjust very well. Some of them, however, at the beginning will be scared since they never been to the forest before and they always have food in the cage, so they will choose to follow the biologists all the time. Afterward, little by little, the monkeys will learn the way to survive in the forest. Some of them may fall down and broke their bones, and biologists will come up to cure them as soon as possible, releasing them again, and they will learn more and live better in the jungle afterwards. Some of the spider monkeys get disappeared because they are too afraid of the new environment and run away, the biologists will then walk around and try to find them and capture them, putting them into the group again.

For the monkeys, finding food in the jungle is not a problem since normally the experts will release the monkeys in November which is the beginning of the rain season. The rain season gives the spider monkeys a lot of food. And even under the harsh condition that there is no food, the spider monkeys can still survive because the existence of ton of leaves which they largely depend on in the forest. The most important thing they help the spider monkeys to do is to maintain a group, thus the monkeys will gain more chance to survive. They will set the spider monkeys free in a protected area, and this will be the release site. They will make a small camp there, and live their everyday for one month, because they know if they are not there, the monkey group will split and separate. If they are there, they will try to stay with them and live next to the camping sites. It is fine because this is just a beginning, just like the child doesn't want to go to the school which normally happens in human society. At first, the spider monkeys will go after you everywhere, but after some time, little by little, when they get more confidence, they will make their scope of activities bigger. The camp site will still be inside their hunt range. And still, some individuals may run away. When that happened, the biologists need to go and find them, bringing them back again until they understand. This is an especially tough process. The time that the staffs who have to stay in the camp is depending on the conditions of the group, normally between 1 and 2 months. And after 3 months, the frequenvy will change to 1 or 2 times per week to check out whether they are still collaborating well with their new living environment.

The spider monkeys can still remember the experts after some time. And when the experts walk in to the deep part in the jungle and deliver a loud and special sound which similar to the sound of monkeys to the wild, the monkeys may come close to them and stay on the trees around the experts. The spider monkeys will get down from the trees if the experts tell them to do so. Apparently, the expert will not try to do this because it is better for the monkeys to keep distance from people after released. During this observation period, the staffs can't see or judge whether their conditions are good or not, but it's enough to make sure. For example, few months before, the experts have 
decided to go into the forest, collecting the data of the group released in 2011 and 2014 and see what they do for now.

So this is how the re-introduction process work, but the target of the work is to re-establish, and re-cooperate with the population here. There were spider monkeys living in this area, and the process is to introduce them into there again.

\section{References}

[1] Baidu: Amazon forest [DB/OL]

[2] Wikipedia: Spider monkey [DB/OL] 